\title{
Genetic polymorphisms of the promoter region of dopamine D2 receptor and dopamine transporter genes and alcoholism among four aboriginal groups and Han Chinese in Taiwan
}

\author{
Wei J. Chen ${ }^{a}$, Chia-Hsiang Chen ${ }^{b}$, Jielen Huang ${ }^{c}$, Yun-Pung P. Hsu ${ }^{d}$, See-Voon Seow ${ }^{c}$, \\ Chiao-Chicy Chen ${ }^{\mathrm{e}}$ and Andrew T.A. Cheng ${ }^{\mathrm{C}}$
}

${ }^{a}$ Institute of Epidemiology, College of Public Health, National Taiwan University, Taipei, Taiwan; ${ }^{b}$ Department of Psychiatry, Tzu-Chi General Hospital, and Institute of Human Genetics, Tzu-Chi Medical College, Hualien City, Taiwan; ${ }^{c}$ Institute of Biomedical Sciences, Academia Sinica, Taipei, Taiwan ${ }^{d}$ Department of Life Science, National Tsing Hua University, Hsinchu, Taiwan; ${ }^{e}$ Department of Adult Psychiatry, Taipei City Psychiatric Center, Taipei, Taiwan

Correspondence to Professor Andrew T.A. Cheng, Institute of Biomedical Sciences, Academia Sinica, Taipei, Taiwan. E-mail: bmandrew@ccvax.sinica.edu.tw

Received 15 January 2001; accepted 7 August 2001

\begin{abstract}
This study aims to examine the relationship between the functional polymorphism at the promoter region of the dopamine $\mathrm{D2}$ receptor (DRD2) gene (i.e. -141C Ins / Del) and variable number of tandem repeat polymorphism at the $3^{\prime}$ untranslated region of the dopamine transporter (DAT) gene (SLC6A3) with alcoholism in a case-control study. The cases $(n=203)$ were alcohol dependents with withdrawal symptoms, and the controls $(n=213)$ were sex- and ethnicity-matched individuals who were screened to exclude those with alcohol problems among four aboriginal groups (Atayal, Ami, Bunun, and Paiwan) and Han Chinese in Taiwan. To control for potential confounding factors, we excluded tobacco abusers from control subjects in part of the analysis and compared the distribution of the genetic polymorphisms in alcoholics with severe medical complications versus those with less severe medical complications. There were no differences in allele and genotype frequencies of these two distinct genetic markers between alcoholics and control subjects in these five different ethnic groups. There was no significant linkage disequilibrium between the -141C polymorphism and two other DRD2 polymorphisms (TaqI A and NcoI). The results remained unchanged when cases were limited to alcoholics with more severe medical complications or when tobacco abusers were excluded from control subjects. The results suggest that both the DRD2 promoter region and the DAT gene do not play a significant role in conferring vulnerability to alcoholism. Psychiatr Genet 11:187-195 (c) 2001 Lippincott Williams \& Wilkins.
\end{abstract}

Keywords: alcoholism, genetics, dopamine D2 receptor, dopamine transporter, promoter

\section{INTRODUCTION}

Alcoholism is a complex mental disorder that most probably results from the interplay between genetic predisposition and environmental factors (Cloninger, 1987; Merikangas, 1990). In search of genetic susceptibility to alcoholism, the dopaminergic neurotransmission in the mesolimbic system has been extensively investigated because of its involvement in the reinforcing effects of rewarding behavior (Koob, 1992; Nestler et al., 1993; Noble, 1996). Animal studies have shown that alcohol can enhance the dopamine release in the rat brain (Brodie et al., 1990; Weiss et al., 1993), alcohol preference and sensitivity are markedly reduced in mice lacking the dopamine D2 receptor (DRD2) (Phillips et al., 1998), and blockade of DRD2 disrupts ongoing alcohol drinking in genetic drinking rat (Myers and Robinson, 1999). The association between the human DRD2 gene and alcoholism was first reported by Blum et al. (1990). They found an allelic association of severe alcoholism with the TaqI A1 allele, which was located $10 \mathrm{~kb}$ downstream of the end of the $3^{\prime}$ untranslated region of the DRD2 gene. However, the results of subsequent association studies have been conflicting, with some replicating and some not replicating the finding (reviewed by Ferguson and Goldberg, 1997; Noble, 1998).

There are several important issues in interpreting 
these findings. First, since there are large variations in DRD2 allele frequencies among population groups (Kidd et al., 1998), the association might be due to confounding by population admixture if cases and control subjects were from different ethnic groups. Nevertheless, combined analyses of independent studies of non-Hispanic Caucasian alcoholics and non-alcoholics have shown the association to be significant (Noble, 1998). However, several familybased association studies employing either the transmission/disequilibrium test or affected familybased association tests, which are free from population stratification, failed to find such an association between the DRD2 gene and alcoholism (Neiswanger et al., 1995; Edenberg et al., 1998; Blomqvist et al., 2000). Second, several studies have reported that the DRD2 A1 allele is associated with a variety of other substance use disorders, such as nicotine, opioids, cocaine, and polysubstances, and it has been stressed that control subjects should be screened to exclude individuals with these drug problems. Third, since alcoholism is a heterogeneous disorder, the association between the DRD2 A1 allele and the disease might exist only in those with more severe alcoholism. However, there is no clear consensus about the definition of severity. Whether the medical complications commonly seen in more severe cases reflect the severity of alcohol dependence per se or are merely a medical consequence of alcohol consumption has been debated (Conneally and Sparkes, 1998).

Given that the TaqI A and other nearby polymorphisms do not affect the protein sequence, it is probable that the association is due to linkage disequilibrium with unknown functional polymorphisms. Recently, a functional polymorphism at the $5^{\prime}$ promoter region of the DRD2 gene was identified by Arinami et al. (1997). The DRD2 promoter polymorphism is a cytosine insertion/deletion ( Ins / Del) variant at the -141 nucleotide position. An expression assay showed that the $\mathrm{C}$ Ins allele has higher functional activity than the $\mathrm{Del}$ allele, indicating that this polymorphism may regulate the DRD2 gene expression in vivo. Ishiguro et al. (1998) found that the $-141 \mathrm{C}$ polymorphism was associated with alcoholism in Japanese. Paradoxically, the trend that the frequency of the $-141 \mathrm{C}$ Ins allele was increased in Japanese alcoholic subjects as compared with control subjects was opposite to that expected. Besides, Ishiguro et al. found that there is no significant linkage disequilibrium between the $-141 \mathrm{C}$ and TaqI A polymorphisms. Several subsequent studies failed to find an association between the $-141 \mathrm{C}$ polymorphism and alcoholism, and could not find linkage disequilibrium between the $-141 \mathrm{C}$ and the TaqI A polymorphisms (Gelernter et al., 1998; Blomqvist et al., 2000; Noble et al., 2000). Given the limited number of studies that have examined this polymorphism in alcoholics, the role of the $-141 \mathrm{C}$ polymorphism of the DRD2 gene in the susceptibility to alcoholism warranted further investigation.

Another way to test the involvement of dopaminergic transmission in alcoholism is to examine genetic polymorphisms of the dopaminergic system other than dopamine receptor. The dopamine transporter (DAT) is located at the presynaptic neuron, and is responsible for the re-uptake of dopamine from the synaptic cleft to terminate the action of dopamine neurotransmission. Abnormal distribution and density of DAT were found in the brain of alcoholics (Tiihonen et al., 1995). Thus, DAT might have interactions with alcohol (Goldman, 1995). The variable number of tandem repeat (VNTR) polymorphisms of the DAT gene (locus symbol SLC6A3) is a 40 bp repeat located at the 3' untranslated region of the DAT1 gene (Vandenbergh et al., 1992). Gelernter et al. (1994) reported an allelic association between the frequency of the nine-repeat allele of the SLC6A3 and cocaineinduced paranoia. Two subsequent population association studies on alcoholism found that either the frequency of the seven-repeat allele of the SLC6A3 was increased in Japanese alcohol-dependent patients with a defective aldehyde dehydrogenase-2 allele (ALDH2*2) (Muramatsu and Higuchi, 1995) or the frequency of the nine-repeat allele of the SLC6A3 was increased in German alcoholic subjects with withdrawal symptoms (Sander et al., 1997). Schmidt et al. (1998) further found that the A9 allele is associated with more severe effects of alcohol withdrawal. However, a recent family-based association study with a new sample of German alcoholics failed to find a significant association of the nine-repeat allele of the SLC6A3 and alcoholism (Franke et al., 1999). Similar to the case for the DRD2 gene, the interpretation of these association studies should be cautioned because there are large variations in SLC6A3 polymorphism frequencies among population groups (Kang et al., 1999). The relationship between the SLC6A3 polymorphism and alcoholism needs further exploration.

In a prior community-based association study, we examined the relationship between two polymorphisms of DRD2 and alcoholism in four aboriginal groups and Han Chinese in Taiwan (Chen et al., 1997a). Features of the study included both cases and control subjects being matched by ethnicity, cases were of sufficient severity (meeting the DSM- 
III-R (American Psychiatric Association, 1987) criteria of alcohol dependence and having withdrawal symptoms), control subjects were screened to exclude individuals with alcohol problems, and tobacco abusers among controls were excluded from part of the analyses. We found a borderline association between alcoholism and TaqI A1 in the Ami $(P=$ $0.08)$ and an association between alcoholism and NcoI N1, located on exon 6 of the DRD2 (Sarkar et al., 1991), in Han Chinese $(P=0.01)$. Results of haplotype analysis further showed that the frequency of haplotype A1N1 was higher in alcoholic subjects than in control subjects for the Ami $(P=$ $0.01)$ and Han Chinese $(P=0.03)$.

To explore the nature of these associations further, in this study we aim to examine the relationship between the functional polymorphism at the promoter region of the DRD2 gene and the VNTR polymorphism of the SLC6A3 with alcoholism using the same sample as our previous study. We also examined whether there is linkage disequilibrium between the DRD2 promoter region and the TaqI A and the NcoI polymorphisms. To further control of potential confounders, we excluded tobacco abusers from control subjects in part of the analysis and compared the distribution of the genetic polymorphisms in alcoholics with severe medical complications versus those with less severe medical complications.

\section{METHODS}

Subjects and clinical assessments

The ascertainment of subjects examined in this study has been described in detail elsewhere (Chen et al., 1996, 1997a,b). In brief, subjects who met the DSMIII-R (American Psychiatric Association, 1987) criteria of alcohol dependence with withdrawal symptoms were included as cases. The control subjects were subjects who had no alcohol problems (either never drank or only occasionally drank in low quantity) and were matched on the basis of ethnicity and sex to cases. Older eligible subjects were preferred as matched controls to avoid misclassification in phenotype. Any subjects born from an inter-ethnic marriage were excluded. Related subjects were also eliminated from eligibility. The alcoholic status of the subjects was assessed by a psychiatrist or welltrained research assistants with a semi-structured clinical interview schedule for alcoholism, which includes the alcoholism section of the Schedules for Clinical Assessment in Neuropsychiatry (World Health Organization, 1999) and other relevant items. The reliability of the instrument has been reported to be satisfactory (Cheng and Chen, 1995; Cheng et al., 2001).

In addition to psychiatric assessment, information on medical complications and smoking history were also collected. As explained in detail in Chen et al. (1997a), we subgrouped the alcoholics as more severe if they had any one of the following complications: (1) impairment of liver function (those without hepatitis B and C virus seropositivity and a combination of an alanine aminotransferase level $>35 \mathrm{IU} / 1$ and an aspartate aminotransferase level $>35 \mathrm{IU} / \mathrm{l}$ ); (2) peripheral neuropathy (if subjects reported that alcohol consumption produced sensations of tingling or numbness in the feet); and (3) hallucinations. These criteria were selected because they could be determined either by laboratory tests or by selfreports of high accuracy in a field survey setting. To exclude a possible confounding by tobacco abuse among controls, those who have smoked at least one pack of cigarettes per day for at least 1 year were deleted from part of the analysis.

The aboriginal subjects were ascertained from either a longitudinal community survey among four aboriginal groups (Atayal, Ami, Bunun, and Paiwan) (Cheng \& Chen, 1995; Chen \& Cheng, 1997), or referred to us via local health workers (Chen et al., 1997b). Almost all cases were identified from the community and many of them have been treated for various complications of alcohol drinking, although few of them had ever been treated for alcoholism per se due to poor accessibility of psychiatric services. The Han alcoholic subjects were recruited from both community (Chinshan and Sanchi Township) and clinical settings (Taipei City Psychiatric Center and Chinshan Health Station) in northern Taiwan, while the Han control subjects were recruited from both the community (Chinshan and Sanchi Township) and the Health Screening Ward at National Taiwan University Hospital (Chen et al., 1996).

In total, 203 alcoholic subjects (168 men and 35 women) and 213 control subjects (178 men and 35 women) were recruited for this study. The mean age for each group ranged from 41.2 to 51.1 years for cases and from 54.2 to 61.0 years for control subjects. However, because of genotyping failure or shortage of DNA material, the actual number of subjects varied for the analysis of the DRD2 promoter and the DAT1 VNTR polymorphisms.

Polymerase chain reaction-based genotyping

Genomic DNA samples extracted from blood were used as templates for polymerase chain reaction 
(PCR) amplification. The genotyping of the functional polymorphism at the promoter region of the DRD2 gene (i.e. -141C Ins / Del) was based on the method described by Arinami et al. (1997) with modification. In brief, PCR was carried out in a volume of $25 \mu \mathrm{l}$ reaction mixture containing sense primer 5'-ACTGGCGAGCAGACGGTGAGGACCC-3' and antisense primer 5'-TGCGCGCGTGAGGCTGCCGGTTCGG-3'. After an initial denaturation at $95^{\circ} \mathrm{C}$ for $5 \mathrm{~min}$, amplification $(30$ cycles) was performed with denaturation at $95^{\circ} \mathrm{C}$ for $1 \mathrm{~min}$, annealing at $68^{\circ} \mathrm{C}$ for $1 \mathrm{~min}$, and extension at $72^{\circ} \mathrm{C}$ for $1 \mathrm{~min}$. The PCR amplification yielded a 304 bp DNA fragment. After amplification, an aliquot (5 $\mu \mathrm{l})$ of PCR product was incubated with BstN1 (New England Biolabs, Beverly, MA, USA) at $60^{\circ} \mathrm{C}$ overnight. The digested PCR products were subjected to electrophoresis in 3\% agarose gel, stained with ethidium bromide, and visualized under UV light. The Ins allele (a cytosine insertion) remained uncut with the size of $304 \mathrm{bp}$, while the Del allele (a cytosine deletion) yielded two DNA fragments of 160 and $144 \mathrm{bp}$.

The PCR-based genotyping of a 40-bp repeat polymorphism at the 3' untranslated region of the human DAT gene was essentially as described by Sano et al. (1993). In brief, PCR amplification was carried out in a $25 \mu \mathrm{l}$ reaction mixture, containing sense primer 5'-TGTGGTGTAGGGAACGGCCTGAGA$3^{\prime}$ and antisense primer $5^{\prime}$-TGTTGGTCTGCAGGCTGCCTGCAT-3'. After initial denaturation at $95^{\circ} \mathrm{C}$ for $3 \mathrm{~min}, 30$ cycles of PCR were carried out with the following conditions: denaturation at $95^{\circ} \mathrm{C}$ for $1 \mathrm{~min}$, annealing at $60^{\circ} \mathrm{C} 1$ for min, and extension at $72^{\circ} \mathrm{C}$ for $1 \mathrm{~min}$. The PCR products were separated in $2 \%$ agarose gel by electrophoresis, stained with ethidium bromide and visualized under UV light with a marker standard on the same gel.

The genotypings of TaqI A and NcoI polymorphism have been described in our previous report (Chen et al., 1997a).

\section{Statistical analysis}

The differences in allele frequency or genotype distribution between cases and controls were examined by Fisher's exact test (two-tailed), and the Hardy-Weinberg equilibrium was tested by the $\chi^{2}$ test with Yates' continuity correction. Frequencies of two-locus haplotype were estimated using Hill's (1974) iteration algorithm. For convenience, we denoted the frequency of the rarer allele at the first locus $p$ and that at the second locus $q: p \leq q \leq 0.5$. The maximum-likelihood estimate of linkage dis- equilibrium statistic $D$ was computed as $D=f_{11}-$ $p q$, where $f_{11}$ is the frequency of the haplotype with the rare allele at both loci. Let $n$ denote number of subjects, the statistic of the test for $D=0$ was (D) $2 n /[p(1-p) q(1-q)]$, which has the $\chi^{2}$ distribution asymptotically with one degree of freedom (df). The maximum possible value of $D$ is $p(1-q)$, denoted as $D_{\max }$, and the percentage of $D_{\max }$ achieved by $D$ is $D^{\prime}=D / D_{\max }$ (Lewontin, 1988). All statistical tests did not adjust for multiple comparisons since the association between the DRD2 gene and alcoholism has been reported previously. $P<$ 0.05 was considered significant, and $P<0.1$ as borderline.

\section{RESULTS}

The genotype distribution of the $-141 \mathrm{C}$ Ins / Del polymorphism of the DRD2 gene did not deviate from Hardy-Weinberg equilibrium in the four aboriginal groups and Han Chinese. Table 1 summarizes the distribution of the genotype and allele frequency of this polymorphism of the DRD2 gene. There were no significant differences in the genotype and allele frequency of this DRD2 polymorphism between alcoholic subjects and control subjects in the five ethnic groups from Taiwan. If we limited the alcoholic cases to those with more severe complications, the difference in genotype distribution between alcoholic subjects and control subjects became borderline for the Atayal $(P=0.09)$.

If control subjects who have had tobacco abuse (one Atayal, one Ami, seven Bunun, two Paiwan, and $15 \mathrm{Han}$ ) are excluded from the analysis, the frequencies of the three genotypes (Ins/Ins, Ins / Del, and $\mathrm{Del} / \mathrm{Del}$ ) were respectively as follows: 0.90, 0.07, and 0.03 for the Atayal; 0.86, 0.14, and 0.00 for the Ami; 0.96, 0.04, and 0.00 for the Bunun; $1.00,0.00$, and 0.00 for the Paiwan; and 0.82, 0.18, and 0.00 for the Han. These were similar to those of the original control subjects. There were no differences in the genotype distribution of the -141C Ins / Del polymorphism of the DRD2 gene between the tobacco-abuse-free control subjects and alcoholic subjects for all five groups. If only more severe cases were included for the comparison, the difference in genotype distribution between alcoholic subjects and the tobacco-abuse-free control subjects remained borderline for the Atayal $(P=$ 0.09).

Since the $-141 \mathrm{C}$ polymorphism is located on the same DRD2 region with TaqI A and NcoI, we further examined whether there was linkage disequilibrium between the $-141 \mathrm{C}$ Ins / Del polymorphism 
GENETIC POLYMORPHISMS OF THE PROMOTER REGION OF DOPAMINE D2 RECEPTOR

TABLE 1. Genotype and allele frequencies of the $-141 \mathrm{C}$ Ins/Del polymorphism of the DRD2 gene among Taiwanese aborigines and Han Chinese

\begin{tabular}{|c|c|c|c|c|c|c|c|c|}
\hline \multirow[t]{2}{*}{ Group } & \multirow[t]{2}{*}{$n$} & \multicolumn{4}{|c|}{ Genotype, $n$ (frequency) } & \multicolumn{3}{|c|}{ Allele frequency } \\
\hline & & Ins/Ins & Ins/Del & Del/Del & $P^{\mathrm{a}}$ & Ins & Del & $P^{\mathrm{a}}$ \\
\hline \multicolumn{9}{|l|}{ Atayal } \\
\hline Control subjects & 30 & $27(0.90)$ & $2(0.07)$ & $7(0.03)$ & & 0.93 & 0.07 & \\
\hline Alcoholic subjects & 39 & $31(0.79)$ & $8(0.21)$ & $0(0.00)$ & 0.13 & 0.90 & 0.10 & 0.55 \\
\hline More severe cases & 19 & $14(0.74)$ & $5(0.26)$ & $0(0.00)$ & 0.09 & 0.87 & 0.13 & 0.30 \\
\hline \multicolumn{9}{|l|}{ Ami } \\
\hline Control subjects & 23 & $20(0.87)$ & $3(0.13)$ & $0(0.00)$ & & 0.93 & 0.07 & \\
\hline Alcoholic subjects & 26 & $21(0.81)$ & $5(0.19)$ & $0(0.00)$ & 0.71 & 0.90 & 0.10 & 0.72 \\
\hline More severe cases & 16 & $11(0.69)$ & $5(0.31)$ & $0(0.00)$ & 0.24 & 0.84 & 0.16 & 0.26 \\
\hline \multicolumn{9}{|l|}{ Bunun } \\
\hline Control subjects & 57 & $54(0.95)$ & $3(0.05)$ & $0(0.00)$ & & 0.97 & 0.03 & \\
\hline Alcoholic subjects & 57 & $53(0.93)$ & $3(0.05)$ & $1(0.02)$ & 1.00 & 0.96 & 0.04 & 0.72 \\
\hline More severe cases & 40 & $38(0.95)$ & $1(0.03)$ & $1(0.03)$ & 0.45 & 0.96 & 0.04 & 0.69 \\
\hline \multicolumn{9}{|l|}{ Paiwan } \\
\hline Control subjects & 35 & $35(1.0)$ & $0(0.00)$ & $0(0.00)$ & & 1.00 & 0.00 & \\
\hline Alcoholic subjects & 36 & $34(0.94)$ & $2(0.06)$ & $0(0.00)$ & 0.49 & 0.97 & 0.03 & 0.50 \\
\hline More severe cases & 20 & $20(1.0)$ & $0(0.00)$ & $0(0.00)$ & 1.00 & 1.00 & 0.00 & 1.00 \\
\hline \multicolumn{9}{|l|}{ Han } \\
\hline Control subjects & 64 & $50(0.78)$ & $14(0.22)$ & $0(0.00)$ & & 0.89 & 0.11 & \\
\hline Alcoholic subjects & 70 & $57(0.81)$ & $13(0.19)$ & $0(0.00)$ & 0.67 & 0.91 & 0.09 & 0.69 \\
\hline More severe cases & 32 & $24(0.75)$ & $8(0.25)$ & $0(0.00)$ & 0.80 & 0.88 & 0.12 & 0.81 \\
\hline
\end{tabular}

${ }^{a} P$-value of Fisher's exact test (two-tailed) comparing control subjects with alcoholic subjects or more severe cases.

and the latter two. Because the frequency of $\mathrm{Del} / \mathrm{Del}$ was very low in all five groups (range, $0-0.03$ ), the frequencies of the haplotypes involving allele $\mathrm{Del}$ were also low. Unlike the significant linkage disequilibrium between the TaqI $\mathrm{A}$ and $\mathrm{NcoI}$ in all five ethnic groups we reported previously $\left(D^{\prime}=\right.$ 0.65-1.00) (Chen et al., 1997a), neither the $D^{\prime}$ value between the $-141 \mathrm{C}$ and TaqI A nor that between the $-141 \mathrm{C}$ and NcoI reached statistical significance, except for one group. The $D^{\prime}$ value between the $-141 \mathrm{C}$ and TaqI A in controls and cases for each group were 1.00 and 0.58 for the Atayal, 0.88 and 1.00 for the Ami, 1.00 and 1.00 for the Bunun, 0.00 and 1.00 for the Paiwan, and 0.42 and 0.58 for the Han, respectively. Only the $D^{\prime}$ value for the Bunun cases reached statistical significance $\left(\chi^{2}=5.75\right.$, $\mathrm{df}=1, P<0.0001)$. The $D^{\prime}$ value between the $-141 \mathrm{C}$ and NcoI in controls and cases for each group were 1.00 and 0.51 for the Atayal, 1.00 and 1.00 for the Ami, 0.16 and 1.00 for the Bunun, 0.00 and 1.00 for the Paiwan, and 0.46 and 0.65 for the Han, respectively. Again, only the $D^{\prime}$ value for the Bunun cases reached statistical significance $\left(\chi^{2}=7.15, \mathrm{df}=1\right.$, $P<0.0001$ ).

The genotype and allele frequencies of VNTR polymorphism at the $3^{\prime}$ untranslated region of SLC6A3 among four aboriginal groups and Han Chinese were summarized in Table 2. In our samples, three alleles were detected, including $490 \mathrm{bp}$
(11 repeats), $450 \mathrm{bp}$ (10 repeats), and $410 \mathrm{bp}$ (nine repeats). The 11-repeat allele was very rare in our subjects; we did not detect this allele in the Atayal, Ami, and Bunun. Only one out of 142 alleles in the Paiwan and six out of 256 alleles in the Han Chinese were found to be 11-repeat alleles. Hence, these individuals with 11 repeats were excluded from comparison. The genotype distribution did not deviate from Hardy-Weinberg equilibrium in both alcoholic subjects and control subjects in these five ethnic groups. There was a borderline difference between alcoholic subjects and control subjects in both the genotype distribution and allele frequency in the Ami $(P=0.09)$. For the remaining ethnic groups, there were no differences in genotype and allele frequencies between alcoholic groups and normal control subjects. If we limited the alcoholic cases to those with more severe complications, the difference in the genotype distribution and allele frequency between alcoholic subjects and control subjects remained borderline for the Ami, although the $P$ value decreased slightly (from 0.09 to 0.07 ).

The frequencies of the three genotypes $(10 \mathrm{x} / 10$ $\mathrm{x}, 10 \mathrm{x} / 9 \mathrm{x}$, and $9 \mathrm{x} / 9 \mathrm{x})$ among the tobacco-abusefree control subjects were respectively as follows: $0.90,0.07$, and 0.03 for the Atayal; 0.82, 0.18, and 0.00 for the Ami; 0.69, 0.29, and 0.02 for the Bunun; $0.90,0.10$, and 0.00 for the Paiwan; and 0.87, 0.11, and 0.02 for the Han. Again, these were similar to 
TABLE 2. Genotype and allele frequencies of the VNTR polymorphism at the $3^{\prime}$ untranslated region of the DAT1 gene among Taiwanese aborigines and Han Chinese

\begin{tabular}{|c|c|c|c|c|c|c|c|c|}
\hline \multirow[t]{2}{*}{ Group } & \multirow[t]{2}{*}{$n$} & \multicolumn{4}{|c|}{ Genotype, $n$ (frequency) } & \multicolumn{3}{|c|}{ Allele frequency } \\
\hline & & $10 x / 10 x$ & $10 x / 9 x$ & $9 x / 9 x$ & $P^{\mathrm{a}}$ & $10 x$ & $9 x$ & $P^{\mathrm{a}}$ \\
\hline \multicolumn{9}{|l|}{ Atayal } \\
\hline Control subjects & 31 & $27(0.87)$ & $3(0.10)$ & $1(0.03)$ & & 0.92 & 0.08 & \\
\hline Alcoholic subjects & 39 & $35(0.85)$ & $6(0.15)$ & $0(0.00)$ & 0.47 & 0.93 & 0.07 & 1.00 \\
\hline More severe cases & 19 & $16(0.84)$ & $3(0.16)$ & $0(0.00)$ & 0.79 & 0.92 & 0.08 & 1.00 \\
\hline \multicolumn{9}{|l|}{ Ami } \\
\hline Control subjects & 23 & $18(0.78)$ & $5(0.22)$ & $0(0.00)$ & & 0.89 & 0.11 & \\
\hline Alcoholic subjects & 26 & $25(0.96)$ & $1(0.04)$ & $0(0.00)$ & 0.09 & 0.98 & 0.02 & 0.10 \\
\hline More severe cases & 16 & $16(1.0)$ & $0(0.00)$ & $0(0.00)$ & 0.07 & 1.0 & 0.00 & 0.07 \\
\hline \multicolumn{9}{|l|}{ Bunun } \\
\hline Control subjects & 56 & $40(0.71)$ & $15(0.27)$ & $1(0.02)$ & & 0.85 & 0.15 & \\
\hline Alcoholic subjects & 56 & $35(0.62)$ & $21(0.38)$ & $0(0.00)$ & 0.31 & 0.81 & 0.19 & 0.59 \\
\hline More severe cases & 40 & $26(0.65)$ & $14(0.35)$ & $0(0.00)$ & 0.71 & 0.83 & 0.17 & 0.69 \\
\hline \multicolumn{9}{|l|}{ Paiwan } \\
\hline Control subjects & 34 & $31(0.91)$ & $3(0.09)$ & $0(0.00)$ & & 0.96 & 0.04 & \\
\hline Alcoholic subjects & 36 & $35(0.97)$ & $1(0.03)$ & $0(0.00)$ & 0.35 & 0.99 & 0.01 & 0.36 \\
\hline More severe cases & 20 & $20(1.0)$ & $0(0.00)$ & $0(0.00)$ & 0.29 & 1.0 & 0.00 & 0.29 \\
\hline \multicolumn{9}{|l|}{ Han } \\
\hline Control subjects & 59 & $51(0.86)$ & $7(0.12)$ & $1(0.02)$ & & 0.92 & 0.08 & \\
\hline Alcoholic subjects & 68 & $56(0.83)$ & $11(0.16)$ & $1(0.01)$ & 0.81 & 0.90 & 0.10 & 0.66 \\
\hline More severe cases & 31 & $25(0.81)$ & $6(0.19)$ & $0(0.00)$ & 0.58 & 0.90 & 0.10 & 0.77 \\
\hline
\end{tabular}

${ }^{a} P$-value of Fisher's exact test (two-tailed) comparing control subjects with alcoholic subjects or more severe cases.

those of the original control subjects. There were no differences in the genotype distribution of the SLC6A3 VNTR polymorphism between the tobacco-abuse-free control subjects and alcoholic subjects, either all cases or more severe ones only, for all five groups.

\section{DISCUSSION}

The continuing controversy over the association between the DRD2 gene and alcoholism is puzzling. On the one hand, there continue to be new results supporting this association. The quantitative trait locus mapping in animal studies consistently demonstrates that the DRD2 gene is responsible for alcohol drinking in rats (Philips et al., 1998; Myers and Robinson, 1999). Although one earlier meta-analysis of human population association studies indicated that the associations between the TaqI A polymorphism and alcoholism of early studies were due to abnormally low control allele frequencies (Gelernter et al., 1993), several later meta-analyses of studies among non-Hispanic Caucasians did find a significant association between the two (Noble, 1998). On the other hand, the magnitudes of association between alcoholism and haplotypes composing of TaqI A and several nearby polymorphisms that are closer to the DRD2 gene per se were less than TaqI A alone (Noble et al., 2000). An earlier study searched for functional polymorphisms in the region of exon 2 to exon 8 in the DRD2 region (Gejman et al., 1994). Although some polymorphisms were found in the exon regions, these were rare and were not associated with alcoholism.

Under this circumstance, the functional polymorphism of the promoter region of the DRD2 gene is of special interest because it has relatively high allele prevalence of the mutant allele. The frequency of the Del allele in the control subjects ranged from 0.0 to 0.11 in the control subjects in the present study, which is close to that in Americans of European origin $(0.11$ by Gelernter et al., 1998) but lower than those in other populations, such as Japanese ( 0.23 by Ishiguro et al., 1998, or 0.21 by Gelernter et al., 1998) and African-Americans (0.39 by Gelernter et al., 1998). Intriguingly, the frequencies of the Del allele in alcoholics of different populations are closer to one another: $0.03-0.10$ in the present study, 0.14 (Ishiguro et al., 1998) in the Japanese, 0.11 in Germans (Blomqvist et al., 2000), and 0.10 in non-Hispanic Caucasians (Noble et al., 2000).

In terms of the potential association between the Ins / Del and alcoholism, however, we did not find a positive association in our samples. This is consistent with two previous studies (Blomqvist et al., 2000; Noble et al., 2000). The only study that reported an association of the $-141 \mathrm{C}$ polymorphism with al- 
coholic subjects was in a subpopulation of Japanese alcoholic subjects (those with ALDH2*2) (Ishiguro et al., 1998). However, the paradoxical direction of the association (higher frequency of the Ins allele rather than the Del allele in alcoholic subjects) renders the finding difficult to explain. Moreover, there is no significant linkage disequilibrium between the $-141 \mathrm{C}$ Ins / Del polymorphism and the TaqI A and NcoI polymorphisms of the DRD2 in our samples. This is indeed consistent with all three previous studies (Gelernter et al., 1998; Ishiguro et al., 1998; Blomqvist et al., 2000; Noble et al., 2000). Taken together, the evidence so far does not support this promoter polymorphism of the DRD2 gene playing a significant role in increasing vulnerability to alcoholism.

In addition, we examined the possible involvement of the DAT gene in alcoholism in our samples. Although positive allelic association of the VNTR polymorphism of SLC6A3 and alcoholism has been reported (Muramatsu and Higuchi, 1995; Sander et al., 1997), the physiological function of the VNTR polymorphism of SLC6A3 remains unknown. Even in these positive studies, the allele that was found to have increased frequency in these two studies was different (the seven-repeat allele in the Japanese alcoholic subjects and the nine-repeat allele in the German alcoholic subjects). However, no positive association with alcoholism was detected in this study. Our results are consistent with those of two family-based association studies (Parsian and Zhang, 1997; Franke et al., 1999). A recent comprehensive search for variations in each of 15 SLC6A3 exons and several introns failed to identify any common protein coding DAT sequence variant in 150 unrelated individuals free of neuropsychiatric disease and 228 patients of various psychiatric disorders (including 64 alcohol dependents) (Vandenbergh et al., 2000). The result indicates that there is substantial evolutionary conservation of the DAT protein sequence. Given the conservation in the coding region of the DAT gene and the failure of several association studies (including this one) to find an association between the VNTR polymorphism of the DAT gene and alcoholism, the possibility that the DAT gene is involved in the susceptibility to alcoholism may lie in its level-of-expression variation. Nevertheless, the SLC6A3 VNTR is a non-functional marker located at one end of the gene and little is known about linkage disequilibrium across this gene. Therefore, the lack of association between the VNTR polymorphism and alcoholism cannot exclude other variation in the gene if it is not in linkage disequilibrium with this VNTR marker.
The conflicting results as seen in many association studies may be attributed to several factors. One is the population admixture due to ethnic heterogeneity in the subjects studied. In this, we use the genetically isolated ethnic groups and chose the appropriate control subjects matched with sex and gender. Moreover, the control subjects were screened to exclude those with alcohol drinking problems. When tobacco abusers were excluded from part of our analyses, the results remained unchanged. Hence, the possibility of false-negative finding in either the DRD2 -141C polymorphism or the SLC6A3 VNTR polymorphism due to population stratification or contaminated control subjects is low in this study. Another issue pertaining to the association studies in alcoholism is whether the alcoholic subjects are of sufficient severity. In this study, we consider all of our alcoholic patients as severe because they all had withdrawal symptoms in addition to satisfying the DSM-III-R criteria of alcohol dependence. Furthermore, if we subgrouped patients into less severe and more severe, and compared the more severe group with control subjects, the results of lack of significant associations between the two genetic polymorphisms and alcoholism remained unchanged.

Two limitations of this study should be noted. First, the sample size of each ethnic group was relatively small. Second, the level of heterozygosity for both the DRD2 -141C Ins/Del and SLC6A3 polymorphisms was low in our samples. Thus, we cannot exclude the possibility of insufficient power to detect the association due to the combination of these two factors.

\section{Acknowledgements}

This work was supported by grants from the National Science Council, Taipei (NSC 89-2320-B001-073). The authors acknowledge the excellent performance of research assistants J.C. Chang, J.Y. Kao and C.L. Cheng in case identification.

\section{REFERENCES}

American Psychiatric Association (1987). Diagnostic and statistical manual of mental disorders, revised. 3rd edn. Washington, DC: American Psychiatric Association.

Arinami T, Gao M, Hamaguchi H, Toru M (1997). A functional polymorphism in the promoter region of the dopamine D2 receptor gene is associated with schizophrenia. Hum Mol Genet 6:577-582.

Blomqvist O, Gelernter J, Kranzler HR (2000). Familybased study of DRD2 alleles in alcohol and drug dependence. Am J Med Genet (Neuropsychiatr Genet) 96:659-664.

Blum K, Noble EP, Sheridan PJ, Montgomery A, Ritchie T, Jagadeeswaran P, et al. (1990). Allelic association of 
human dopamine D2 receptor gene in alcoholism. $J A m$ Med Assoc 263:2055-2060.

Brodie MS, Shefner SA, Dunwiddie TV (1990). Ethanol increases the firing rate of dopamine neurons of the rat. Brain Res 508:65-69.

Chen WJ, Cheng ATA (1997). Incidence of first onset alcoholism among Taiwanese aborigines. Psychol Med 27:1363-1371.

Chen WJ, Loh EW, Hsu Y-PP, Chen C-C, Yu J-M, Cheng ATA (1996). Alcohol-metabolizing genes and alcoholism among Taiwanese Han Men: independent effect of $\mathrm{ADH} 2, \mathrm{ADH} 3$, and $\mathrm{ALDH} 2 . \mathrm{Br} J$ Psychiatry 168:762-767.

Chen WJ, Lu ML, Hsu Y-PP, Chen C-C, Yu J-M, Cheng ATA (1997a). Dopamine D2 receptor gene and alcoholism among four aboriginal groups and Han in Taiwan.Am J Med Genet (Neuropsychiatr Genet) 74:129-136.

Chen WJ, Loh EW, Hsu Y-PP, Cheng ATA (1997b). Alcohol dehydrogenase and aldehyde dehydrogenase genotypes and alcoholism among Taiwanese aborigines. Biol Psychiatry 41:703-709.

Cheng ATA, Chen WJ (1995). Alcoholism among four aboriginal groups in Taiwan: high prevalences and their implications. Alcohol Clin Exp Res 19:81-91.

Cheng ATA, Tien AY, Chang CJ, Brugha TS, Cooper JE, Lee CS, et al. (2001). Cross-cultural implementation of a Chinese version of the Schedules for Clinical Assessment in Neuropsychiatry (SCAN) in Taiwan. Br J Psychiatry 178:567-572.

Cloninger CR (1987). Neurogenetic adaptive mechanisms in alcoholism. Science 236:410-416.

Conneally PM, Sparkes RS (1998). General discussion. Alcohol 16:85-91.

Edenberg HJ, Foroud T, Koller DL, Goate A, Rice J, Eerdewegh PV, et al. (1998). A family-based analysis of the association of the dopamine D2 receptor (DRD2) with alcoholism. Alcohol Clin Exp Res 22:505-512.

Ferguson RA, Goldberg DM (1997). Genetic markers of alcohol abuse. Clin Chim Acta 257:199-250.

Franke P, Schwab SG, Knapp M, Gansicke M, Delmo C, Zill P, et al. (1999). DAT1 gene polymorphism in alcoholism: a family-based association study. Biol Psychiatry 45:652-654.

Gejman PV, Ram A, Gelernter J, Friedman E, Cao Q, Pickar D, et al. (1994). No structural mutation in the dopamine D2 receptor gene in alcoholism or schizophrenia. J Am Med Assoc 271:204-208.

Gelernter J, Goldman D, Risch N (1993). The A1 allele at the D2 dopamine receptor gene and alcoholism: a reappraisal. J Am Med Assoc 269:1673-1677.

Gelernter J, Kranzler HR, Satel AL, Rao PA (1994). Genetic association between dopamine transporter protein alleles and cocaine-induced paranoia. Neuropsychopharmacology 11:195-200.

Gelernter J, Kranzler H, Cubells JF, Ichinose H, Nagatsu T (1998). DRD2 allele frequencies and linkage disequilibria, including the $-141 \mathrm{C}$ Ins /Del promoter polymorphism, in European-American, African-American, and Japanese subjects. Genomics 51:21-26.

Goldman D (1995). Dopamine transporter, alcoholism and other diseases. Nat Med 1:624-625.

Hill WG (1974). Estimation of linkage disequilibrium in randomly mating populations. Heredity 33:229-239.

Ishiguro H, Arinami T, Saito T, Akazawa S, Enomoto M, Mitushio H, et al. (1998). Association study between the
-141C Ins/Del and TaqI A polymorphisms of the dopamine D2 receptor gene and alcoholism. Alcohol Clin Exp Res 22:845-848.

Kang AM, Palmatier MA, Kidd KK (1999). Global variation of a 40-bp VNTR in the $3^{\prime}$-untranslated region of the dopamine transporter gene (SLC6A3). Biol Psychiatry 46:151-160.

Kidd KK, Morar B, Castiglione CM, Zhao H, Pakstis AJ, Speed WC, et al. (1998). A global survey of haplotype frequencies and linkage disequilibrium at the DRD2 locus. Hum Genet 103:211-227.

Koob GF (1992). Drugs of abuse: anatomy, pharmacology and function of reward pathways. Trends Pharmacol Sci 13:177-184.

Lewontin RC (1988). On measures of gametic disequilibrium. Genetics 120:849-852.

Merikangas KR (1990). The genetic epidemiology of alcoholism. Psychol Med 20:11-22.

Muramatsu T, Higuchi S (1995). Dopamine transporter gene polymorphism and alcoholism. Biochem Biophys Res Commun 211:28-32.

Myers RD, Robinson DE (1999). Mmu and D2 receptor antisense oligonucleotides injected in nucleus accumbens suppress high alcohol intake in genetic drinking HEP rats. Alcohol 18:225-233.

Neiswanger K, Hill SY, Kaplan BB (1995). Association and linkage studies of the TaqI A1 allele at the dopamine D2 receptor gene in samples of female and male alcoholics. Am J Med Genet (Neuropsychiatr Genet) 60:267-271.

Nestler EJ, Hope BT, Widnell KL (1993). Drug addiction: a model for the molecular basis of neural plasticity. Neuron 11:995-1006.

Noble EP (1996). Alcoholism and the dopaminergic system: a review. Addict Biol 1:333-348.

Noble EP (1998). The D2 dopamine receptor gene: a review of association studies in alcoholism and phenotypes. Alcohol 16:33-45.

Noble EP, Zhang X, Ritchie TL, Sparkes RS (2000). Haplotypes at the DRD2 locus and severe alcoholism. Am J Med Genet (Neuropsychiatr Genet) 96:622-631.

Parsian A, Zhang ZH (1997). Human dopamine transporter gene polymorphism (VNTR) and alcoholism. Am J Med Genet (Neuropsychiatr Genet) 74:480-482.

Phillips TJ, Brown KJ, Burkhart-Kasch S, Wenger CD, Kelly MA, Rubinstein M, et al. (1998). Alcohol preference and sensitivity are markedly reduced in mice lacking dopamine D2 receptors. Nat Neurosci 1:610-615.

Sander T, Harms H, Podschus J, Finckh U, Nickel B, Rolfs A, et al. (1997). Allelic association of a dopamine transporter gene polymorphism in alcohol dependence with withdrawal seizures or delirium. Biol Psychiatry 41:299-304.

Sano A, Kondoh K, Kakimoto Y, Kondo I (1993). A 40-nucleotide repeat polymorphism in the human dopamine transporter gene. Hum Genet 91:405-406.

Sarkar G, Kapelner S, Grandy DK, Marchionni M, Civelli O, Sobell JL, et al. (1991). Direct sequencing of the dopamine D2 receptor (DRD2) in schizophrenics reveals three polymorphisms but no structural change in the receptor. Genomics 11:8-14.

Schmidt LG, Harms H, Kuhn S, Rommelspacher H, Sander T (1998). Modification of alcohol withdrawal by the A9 allele of the dopamine transporter gene. Am J Psychiatry 155:474-478.

Tiihonen J, Kuikka J, Bergstrom K, Hakola P, Karhu J, Ryynanen O-P, Fohr J (1995). Altered striatal do- 


\section{GENETIC POLYMORPHISMS OF THE PROMOTER REGION OF DOPAMINE D2 RECEPTOR}

pamine re-uptake site densities in habitually violent and non-violent alcoholics. Nat Med 1:654-657.

Vandenbergh DJ, Persico AM, Hawkins AL, Griffin CA, Li X, Jabs EW, Uhl GR (1992). Human dopamine transporter gene (DAT1) maps to chromosome $5 \mathrm{p} 15.3$ and display a VNTR. Genomics 14:1104-1106.

Vandenbergh DJ, Thompson MD, Cook EH, Bendahhou E, Nguyen T, Krasowski MD, et al. (2000). Human dopamine transporter gene: coding region conservation among normal, Tourette's disorder, alcohol dependence and attention-deficit hyperactivity disorder populations. Mol Psychiatry 5:283-292.

Weiss F, Lorang MT, Bloom FE, Koob GF (1993). Oral alcohol self-administration stimulates dopamine release in the rat nucleus accumbens: genetic and motivational determinants. J Pharmacol Exp Therap 267:250-258.

World Health Organization (1999). SCAN 2.1: schedules for clinical assessment in neuropsychiatry. Cambridge: Cambridge University Press. 